\title{
A morphospace of planktonic marine diatoms. I. Two views of disparity through time
}

\section{Citation}

Kotrc, Benjamin, and Andrew H. Knoll. 2015. "A Morphospace of Planktonic Marine Diatoms. I. Two Views of Disparity through Time." Paleobiology 41 (01) (January): 45-67. doi:10.1017/ pab.2014.4.

\section{Published Version}

doi:10.1017/pab.2014.4

\section{Permanent link}

http://nrs.harvard.edu/urn-3:HUL.InstRepos:16953007

\section{Terms of Use}

This article was downloaded from Harvard University's DASH repository, and is made available under the terms and conditions applicable to Open Access Policy Articles, as set forth at http:// nrs.harvard.edu/urn-3:HUL.InstRepos:dash.current.terms-of-use\#OAP

\section{Share Your Story}

The Harvard community has made this article openly available.

Please share how this access benefits you. Submit a story.

\section{Accessibility}


Kotrc and Knoll 1

1 A morphospace of planktonic marine diatoms, part I: Two views of disparity through time

Benjamin Kotrc and Andrew H. Knoll

3

4 RRH: DIATOM MORPHOSPACE PART I: DISPARITY

5 LRH: BENJAMIN KOTRC AND ANDREW H. KNOLL 
7 Abstract.-Both molecular clocks and the first appearances of major groups in the fossil record suggest that most of the range of diatom morphologies observed today had evolved by the end of the Cretaceous Period. Despite this, a canonical reading of the Cenozoic fossil record suggests a dramatic rise in taxonomic diversity that can be interpreted as an explosion of morphological variety. We investigated this apparent discrepancy using a discrete-character-based, empirical diatom morphospace, resolved by molecular phylogeny and by fossil occurrences through time. The morphospace shows little correspondence to phylogeny and little Cenozoic change in disparity as measured by mean pairwise distance. There is, however, an increase in the total volume of morphospace occupied. Although the increase in occupied volume through time ostensibly supports a conclusion of increasing morphological variety, sampling biases and other data suggest an underlying stationary pattern more consistent with molecular clock data.

Benjamin Kotrc. Department of Earth and Planetary Sciences, Harvard University, Cambridge, Massachusetts 02138 U.S.A. Present address: Department of Earth, Atmospheric and Planetary Sciences, Massachusetts Institute of Technology, Cambridge, Massachusetts 02139 U.S.A. E-mail: kotrc@mit.edu 


\section{Introduction}

Diatoms are a diverse and ecologically important part of the marine phytoplankton, responsible for a substantial proportion of Earth's total photosynthesis (ca. 10-20\%, according to estimates of Raven 2003 and Nelson 1995). Beyond their significance at the base of the food web, diatoms are important to the global carbon cycle because they sink readily and thus export carbon from the surface ocean (Dugdale and Wilkerson 1998). This is due in part to their relatively large cell size and growth in chains and blooms, but also to the ballast provided by their silicified cell walls, or frustules.

Diatom frustules are highly preservable and can accumulate in great numbers in marine sediments, endowing marine planktonic diatoms with an extensive fossil record that stretches back at least to the early Cretaceous Period. Their abundance and morphological diversity makes them useful as biostratigraphic markers, particularly in the Cenozoic Era, and thus extensive data exist about their occurrence through time. The Neptune database (Lazarus 1994; Spencer-Cervato 1999), for example, is a compilation of tens of thousands of records of diatom occurrences in sediment cores drilled by the Deep Sea and Ocean Drilling Programs (DSDP and ODP) that provides a rich and readily available data set for macroevolutionary studies representing the combined output of many decades of micropaleontological effort.

Diatom fossils have been used to address a number of questions - including their diversity history (Spencer-Cervato 1999), biostratigraphy (Fenner 1985; Barron 1985), coevolution with cetaceans (Marx and Uhen 2010), and the Cenozoic silica cycle (Harper and Knoll 1975; Lazarus et al. 2009); however, a fundamental macroevolutionary question remains unresolved: the relationship between diatoms' taxonomic and morphological diversification. 
Because fossil taxa are defined morphologically, the number of distinct taxa is, by definition, a measure of morphological variety. But this variety can also be measured with more nuance by quantifying aspects of shape directly and then summarizing these measurements by a variety of disparity metrics (Erwin 2007). Both diversity and disparity have been used in macroevolutionary studies of groups with extensive fossil records, including the biomineralizing microplankton. The two measures provide different views of evolutionary change through time, and do not necessarily co-vary.

On the contrary, many examples of decoupled changes in diversity and disparity have been documented; clades commonly fill morphological space rapidly at low taxonomic diversity early in their history (reviewed in Foote 1997: p. 137), a pattern referred to as "asymmetric diversification" (Webster 2007). Perhaps the most famous large-scale example is the Cambrian explosion, when the major animal body plans evolved early (high disparity), leaving the rest of the Phanerozoic to play out in relative macromorphological stasis while taxonomic diversity increased (e.g., Gould 1989; Erwin et al. 2011). In this study, we examine whether this pattern is also common to the diatoms.

The history of diatom taxonomic diversity has conventionally been taken to support a pattern of major morphological diversification late in the group's history, associated with a steep rise in ecological prominence through the Cenozoic Era. Other lines of evidence, however, suggest that diatoms may have remained broadly morphologically unchanged over the past 65 million years: both molecular clocks (Kooistra and Medlin 1996; Sorhannus 2007) and fossil discoveries (reviewed in Sims et al. 2006) suggest that all major morphological groups of diatoms were present by the end of the Paleocene Epoch. The question of whether the suggested Cenozoic evolutionary history of the diatoms is better described as stationary or diversifying has become increasingly intriguing with recent work suggesting that the Cenozoic rise in taxonomic 
diversity may largely be an artifact of sampling bias (Rabosky and Sorhannus 2009). This makes

clear the need for a different — morphological—window on the Cenozoic evolutionary history of the diatoms. In this study, we review the evidence for unchanging diversity as well as for increasing diversity, and use a morphospace to gain a more differentiated view of Cenozoic diatom evolution.

\section{Diatom Diversity and Disparity}

The Importance of Frustule Shape

The shape of the diatom frustule is ecologically and thus evolutionarily important because the frustule performs a variety of functions. Indeed, the frustule has been implicated as a key innovation allowing the diatoms to rise to their present-day ecological importance (Kooistra et al. 2007; Hamm and Smetacek 2007). While the diatom frustule has not been definitively shown to perform any one single function to the exclusion of all others, a number of evolutionary hypotheses have been presented, which can be summarized under two major headings: those based on a top-down view of diatom evolution, driven by predation, and those based on a bottomup view, driven by resource competition.

The top-down view sees the frustule as a way to decrease mortality, providing defense against the crushing mouthparts of grazers through mechanical strength and deterrent spines (Smetacek 2001; Hamm et al. 2003) and a rigid barrier against pathogens or parasites (Smetacek 1999). The ballast provided by frustules may also facilitate the sinking of infected cells from surface populations (Raven and Waite 2004). In contrast, the bottom-up view sees the frustule as a key to the diatoms' ability to take up nutrients rapidly and store them over several generations by providing ballast to counteract the buoyancy of the vacuole and rigidity against its turgor 
pressure (Raven and Waite 2004), as well as allowing cells to sink out of depleted surface waters to nutrient-enriched depths (Raven 1997; Raven and Waite 2004).

\section{History of the Major Diatom Groups}

Mesozoic Origins.-Diatoms have been divided into four major taxonomic groups characterized by different gross morphological types: forms with round (1), multi-angled (2), or bilaterally symmetrical (3) outlines, and slit-bearing (4) forms. The frustules of radial centric diatoms (1) have a ring-shaped structural "pattern center" (an imperforate siliceous structure from which the ribs giving rise to the rest of the frustule originate during morphogenesis). The two valves making up the frustule are generally circular in plan view, i.e., they are radially symmetrical. The bi- and multipolar centrics (2) share the same ring-shaped pattern center, but have valves that are commonly elongated and distorted in plan view, often with well-delimited areas of smaller pores that seem to be involved in mucilage secretion. The pennate diatoms (3) are characterized by a linear pattern center and generally have a bilaterally symmetrical (pennate meaning feather-shaped) valves. The raphid diatoms (4), a subgroup of the pennates, possess a slit in the surface of the valve through which part of the protoplasm can be extruded for locomotion.

Molecular phylogenies broadly agree on an order of divergence for these four major groups (Medlin and Kaczmarska 2004; Damsté et al. 2004; Sorhannus 2004). The raphid pennates appear to form a monophyletic group, and while the radial centrics form a clade in some treatments, the bi- and multipolar centrics and the araphid pennates are generally considered to be paraphyletic. While they differ in many details, published molecular phylogenies of diatoms all show the radial centric diatoms as basal; bi- and multipolar centrics diverge from within or are sister to the radial centrics. Pennate diatoms are nested within the bi- and multipolar centrics, 
with raphid pennates forming a derived clade within the pennates. These relationships predict an order of first appearances for these four groups that is confirmed by the fossil record (Sims et al. 2006).

Both molecular clocks and the fossil record indicate that the four major groups (and thus highest-level taxa) of diatoms had evolved by the earliest Cenozoic Era. The most recent molecular-clock estimates of divergence times (Sorhannus 2007) suggest that all four major groups appeared in the Mesozoic Era, while actual first appearances based on fossils postdate these estimates by 10-40 Myr. The oldest fossil diatom accepted by Sims et al. (2006) is a radial centric from Liassic shales in Germany (Rothpletz, 1896), roughly the same age as that predicted by Sorhannus' molecular clock. Molecular divergence times for bi- and multipolar centrics are around 40 Myr before their Aptian-Albian first appearance (Gersonde and Harwood 1990), for pennate diatoms, also some $40 \mathrm{Myr}$ before their Campanian first appearance (Sims et al. 2006), and for raphid pennates about $10 \mathrm{Myr}$ before their first appearance in the Paleocene of Russia (Pantocsek, 1886; Witt, 1886). The magnitude of these differences between the molecular and fossil estimates of first appearance is comparable to other groups (Sperling et al. 2011, for example, cite around $20 \mathrm{Myr}$ for early brachiopods), particularly considering that open ocean habitats may encourage longer gaps between speciation and first appearance in the fossil record (Anderson et al. 2011).

Given the largely Mesozoic origin of the four major diatom taxa, and the gross morphotypes they represent, we might expect a relatively stationary pattern of morphospace occupation through Cenozoic time (though we do not necessarily expect this for characters not describing gross morphology).

Cenozoic Events.-Following the Mesozoic establishment of the four major groups, the molecular and fossil records show three major Cenozoic events in diatom evolution, according to 
142 Sims et al. (2006) and Kooistra et al. (2007): (1) the invasion of fresh water, unlikely to have influenced morphological diversity in the open ocean (in any case, fossil evidence suggests it may have begun earlier than commonly thought; Chacón-Baca et al. 2002, Chang et al. 2003), (2) the evolution of the Thalassiosirales (a subgroup of the bi- and multipolar centric diatoms with a round outline that is ecologically important in modern oceans), and (3) the diversification of raphid diatoms, the most important of these events because of the great diversity in that group.

\section{Cenozoic Taxonomic Diversity}

The unchanging Cenozoic planktonic diatom morphospace suggested by molecular clocks stands in stark contrast to a canonical reading of the Cenozoic record of planktonic diatom diversity. The record of diatom species diversity has long been interpreted as an almost monotonic increase through the Cenozoic Era (Small 1946; Spencer-Cervato 1999), though this view has been recently challenged by Rabosky and Sorhannus (2009). This canonical view has been widely accepted and marshalled as evidence, for example, in explanations of Cenozoic decline in marine silicic acid concentrations (Harper and Knoll 1975; Lazarus et al. 2009) and the evolution of modern phytoplankton (Falkowski et al. 2004). Such explanations of Cenozoic diatom evolution imply that their sharp rise in diversity is a proxy for dramatic environmental expansion and success. In so far as ecology and morphology are linked, it would be reasonable to expect that ecological diversification would go hand in hand with an increased diversity of form.

The canonical reading of the diatom diversity record, therefore, implies a major ecological expansion of the diatoms in Cenozoic Era, and, if not directly requiring an expansion of morphospace, certainly suggests it.

In this study we test the hypothesis that, in spite of apparently increasing taxonomic diversity, disparity and morphospace occupancy of marine planktonic diatoms were stationary 
through the Cenozoic Era. Prior morphospace studies on diatoms, including both theoretical (Pappas 2005) and empirical (Du Buf and Bayer 2002) morphospaces, were limited either to particular lineages or studies of valve outlines and pennate striations, ignoring the many other features of frustules. Because of the diversity and complexity of structures comprising the diatom frustule, we opt to describe diatom morphology using discrete characters (on the nominal scale of Stevens 1946). We use the record of diatom occurrences provided by the Neptune database to quantify occupancy of this morphospace through time. In order to cover the full breadth of morphologies captured by this record, we work at the genus level and use the diatom genera found in the Neptune database to construct a morphospace. We first discuss ways of visualizing morphospace to depict more explicitly the morphological meaning of morphospace ordinations. With this more intuitive sense, we interpret the history of Cenozoic diatom disparity.

\section{Materials and Methods}

The full range of morphologies a group of organisms can have is often described as a morphospace: a vector space defined by axes representing an aspect or measurement of the organism. Each point in these spaces represents a distinct morphology, which may or may not be occupied by an organism. A distinction is commonly made between theoretical and empirical morphospaces, with axes in the former represting parameters of a geometric model of organism shape (e.g. Raup and Michelson 1965), while in the latter each axis represents a measurement of some sort. Theoretical morphospaces have relatively few dimensions, while empirical morphospaces tend to have many and thus require ordination to be visualized in two dimensions. While there has been some debate about the relative merits of theoretical versus empirical morphospaces (e.g., McGhee 1999), they can be considered as different manifolds within a "true" phenotypic morphospace comprised of more dimensions than can either be modeled or measured. 
Either a theoretical or an empirical morphospace may be the most relevant representation of a range of morphologies, depending on the organisms and the research questions at hand.

\section{The Neptune Database}

Documenting the occupation of morphospace through time requires measures of a taxon's morphology as well as stratigraphic range. In many morphospace studies published to date, the latter has been achieved through range compilations, inferring a taxon's duration based on first and last occurrences (e.g., Foote 1993 1995a; Smith and Bunje 1999; Eble 2000). Over the past two decades, however, paleobiologists have begun to assemble and use large databases of fossil occurrences so as to address secular differences in sampling. In this study we thus use an occurrence-based database to populate a morphospace through time.

The Neptune database provides a record of Cenozoic planktonic diatom occurrences. Sampling intensity in Neptune is not uniform through time: the number of samples decreases substantially with age, in part because older seafloor is more likely to have been subducted. Because more recent sediments are found almost everywhere on the ocean floor, any drilling operation to older sediments will also penetrate younger sediments, inflating the number of younger samples.

We constructed a morphospace using discrete characters, populating it through time using the occurrence data from the Neptune database. We coded 123 discrete morphological characters for 152 diatom genera using descriptions from the taxonomic literature. These genera represent all the valid genera found in the Neptune database (Lazarus 1994; Spencer-Cervato 1999), plus those found in the three published Cretaceous diatom assemblages recovered by the DSDP/ODP program (Hajós 1976; Gersonde and Harwood 1990; Fourtanier 1991). Genera described as resting stages, which represent a non-vegetative stage of the life cycle and sometimes radically 
different morphologies, were excluded from the analysis. By linking these morphological data with the fossil occurrence data in the Neptune database, we were able to reconstruct diatom morphospace through time in the open ocean. Over $95 \%$ of the diatom occurrences in the Neptune database are from cores drilled at water depths $>1000 \mathrm{~m}$ (and 70\% from depths $>2000 \mathrm{~m}$ ); thus, the evolution of diatoms in coastal and terrestrial environments may have followed quite different trajectories.

\section{Choice of Characters}

We compiled a list of morphological characters from general descriptions of frustule morphology (Barber and Haworth 1981; Anonymous 1975) and taxonomic descriptions of the chosen genera. To avoid introducing bias from the taxonomic structure inherent in commonly used terminology, we formulated morphological characters as generally as possible.

For many aspects of diatom morphology, the same shape or structure is given different names in the literature depending on taxonomic grouping. For example, some authors use almost non-overlapping vocabularies in describing pores and their arrangement on the frustule in centric and pennate diatoms, although the structures are obviously comparable (see, for example, Anonymous 1975). Since coding separate characters for "areolation" (p. 348, ibid.) vs. "striation" (p. 349, ibid.) would introduce an artificial separation between similar structures, we instead created generally applicable characters for "pore arrangement". This single set of characters can represent the morphologies bearing different sets of names in the two groups. We applied a similar, taxonomically agnostic approach to other cases where the terminology used in the literature for similar structures differs among genera because the structures differ developmentally, are not considered homologous, or simply occur in different taxa. 

(i.e., they are measurements on the nominal scale, Stevens 1946). Although all missing data were treated equally in the analysis presented below, we distinguished among three different types in the morphological data matrix: character states not observed because of missing information, logically inapplicable character states, and character states varying within or between species of a genus with no obviously predominant state. Rather than excluding all missing data, as we did, an alternative approach is to include 'logically inapplicable' as a distinct character state in pairwise comparions (Deline 2009). This approach results in a greater effect in the analysis of morphological features described by multiple subsidiary character states. While this can be considered desirable, we chose our approach precisely to avoid giving greater weight to some morphological features over others, because they may be better-described in the literature, and thus have multiple subsidiary states, due to reasons other than ecological or evolutionary importance (such as taxonomic convenience). A description of each character and the complete morphological data matrix are provided in the online supplement.

We coded the morphological character states for each genus based on descriptions from the taxonomic literature. For 64 of the 152 genera investigated, we used descriptions provided in the standard text by Round et al. (1990). For the remaining genera, we consulted the wider literature, usually the original generic description as well as the most detailed or recent study available, and sought SEM images wherever possible. A complete listing of the sources consulted for each genus is provided in the online supplement.

Because of the sources of incomplete data mentioned above, some of the genera in the data matrix had relatively few characters with valid states. Likewise, a number of the characters 
had valid states for only a few genera. In order to avoid including relatively uninformative genera and characters, we removed genera and characters with less than $80 \%$ observed entries. The implications of setting data culling thresholds have been discussed by Ciampaglio et al. (2001) and are investigated in detail in the companion paper in this issue. The culled data matrix consists of 140 genera and 100 characters.

Occurrence Data

Diatom occurrence data, used in the analysis to determine how the morphospace became occupied through time, were downloaded from the Neptune database via http://portal.chronos.org/ in May 2009 (subsequent changes to the database as a part of the Neptune Sandbox project are not yet publically accessible, but have resulted in a data set "similar in content to the Chronos Neptune database" according to Lazarus et al. 2014). We made a substantial number of changes, including correcting misspelled genus names, eliminating occurrences with an assigned age of zero (signifying missing age data, according to D. Lazarus, pers. comm.), eliminating taxa incorrectly classified as diatoms, and eliminating taxa considered to be resting stages rather than vegetative cells (according to Hargraves 1986; Harwood 1988; Hendey and Simonsen 1972; Suto 2004 and 2005; Suto et al. 2009 and 2011). Because the Neptune database only contains diatom occurrences from the Cenozoic Era, compound taxon lists from the three described Cretaceous DSDP/ODP assemblages were added to the occurrence dataset (Hajós and Stradner 1975; Gersonde and Harwood 1990; Fourtanier 1991). 

the plotting software, are provided in the online supplement.

Low-Dimensional Representation of the Morphospace

We used principal coordinates analysis (PCO) to plot the 100-dimensional, nominal-scale morphospace (consisting of discrete, unordered characters) defined by the morphological data matrix in two or three continuous dimensions. In the better-known principal components analysis (PCA), an $\mathrm{m} \times \mathrm{n}$ data matrix is transformed directly (where $\mathrm{m}$ is the number of genera and $\mathrm{n}$ is the number of characters). In contrast, the algorithm for PCO (Gower 1966) operates on an $\mathrm{m} \times \mathrm{m}$ matrix of pairwise dissimilarities between taxa; these dissimilarities can be Euclidean distances (producing an equivalent result to PCA) or, as in the present case, a different metric of dissimilarity. We used the sum of character state mismatches divided by the number of possible matches (i.e., excluding comparisons with invalid character states) as the measure of dissimilarity, also used, for example, by Foote (1999), Lupia (1999), and Boyce and Knoll (2002). This dissimilarity metric has the advantage that it accounts for similarity where a valid comparison can be made, but does not inflate dissimilarity by scoring mismatched states where one taxon has invalid or inapplicable states. well the first two axes represent the full space: one can either compare the eigenvalues associated with PCO axes or correlate distances in PCO-space with original distances. The methods give slightly different results. 
The first approach - compareing the eigenvalues associated with first two principal

coordinate axes to those associated with the higher axes (Fig. 1A) — provides a qualitative assessment of the variance associated with each axis, showing that the eigenvalues drop rapidly, although the higher axes are not negligible. One way to quantify this is to divide the sum of the first two eigenvalues by the sum of all eigenvalues (as done by Boyce and Knoll 2002; Foote 1995a), giving an estimate that $26 \%$ of the total variance is explained by the first two principal coordinate axes. However, only 63 of the 140 eigenvalues are positive (see Fig. 1A). This could be due to several reasons: first, we should not expect more positive eigenvalues than characters; second, there were missing data; and finally, because the dissimilarity metric chosen is non-

Euclidean, there may not be an arrangement in the (Euclidean) PCO-space that corresponds to the calculated dissimilarities.

There are several ways to deal with these negative eigenvalues in estimating the information from the original data matrix in the principal coordinate axes. The cmdscale() function that carries out PCO in R, for example, calculates a "goodness of fit" statistic in two ways that are both different from the above: either negative eigenvalues are ignored, which results in the estimate of variance explained dropping to $18 \%$, or the sum of the absolute values of the eigenvalues is used instead, in which case the estimate drops even further to $14 \%$. An empirical alternative for estimating the information retained by the principal coordinate axes is to calculate the correlation between pairwise distances among genera in the original dissimilarity matrix and the pairwise distances of the same genera in PCO-space (Foote 1999). As expected, including progressively more principal coordinate axes increases the correlation (Fig. 1B). This approach suggests that the first two principal coordinate axes explain about $37 \%$ of the variance in the original dissimilarity matrix, a higher value than the estimates based on comparing eigenvalues. 

it not possible to plot "loadings" (the projection of the the original character axes into the lowerdimensional space), as commonly done for PCA, because our characters are discrete, unordered, and contain missing data, Foote $(1995 \mathrm{~b} ; 1999)$ suggested an analogous approach to discover which characters are associated with which PCO axis. The idea is to compare the character states of taxa for each character with the PCO scores of taxa using a nonparametric measure of correlation. One such measure is the Cramér coefficient, which can be used to measure the degree of association between attributes which are measured in unordered categories ( Siegel and Castellan Jr. 1988, p. 225). We calculated this measure for each pairing of characters and PCO axes. In order to discretize the PCO scores, we divided each axis into four arbitrary intervals of equal length. We then constructed a $\mathrm{j} \times 4$ contingency table, where $\mathrm{j}$ is the number of valid character states for the character in question. Entries in the table are counts of the number of genera, for example, with character state 0 and falling in the lowest quarter of the range of the PCO axis. Measuring an association between score on the PCO axis and character state requires at least two columns in this contingency table to have nonzero sums, which is why characters that had fewer than two states with valid entries were culled from the dataset. From this table, we calculated a Cramér coefficient and an associated $p$-value using the assocstats() function in the $\mathrm{R}$ package vcd (Meyer et al. 2011). The results of the 6426 pairwise comparisons are summarized in Figure 2.

While the associations between morphological characters and PCO axes are strongest in the lower axes, there are also significant associations with higher axes. The largest and darkest circles on Figure 2 mark the strongest and most significant associations between characters and particular PCO axes. Broadly, there are more significant associations with the lower PCO axes, corroborating the results described above. This can be seen in two ways, either by noting that 
most of the dark circles are to the left of the plot, or by noting that both the height and darkness of the bars plotted beneath the $\mathrm{x}$-axis increase to the left.

Regardless of the method used, the estimates all suggest that there is significant information contained in the PCO axes beyond the two or three dimensions that can be plotted practically. Such plots will provide a general indication of the arrangement of genera in morphospace rather than a comprehensive summary of the original data matrix. However, the observation that there is information in higher PCO axes suggests there is important complexity in the original data set (as opposed to a handful of powerfully explanatory characters), and this suggests that a future effort to consider this information is warranted.

Interpretation of PCO Axes.-Perhaps the most common criticism of ordinated or empirical morphospaces is that their axes are data-dependent (McGhee 1999; Wilson and Knoll 2010), but a related and more practical problem is that their axes are hard to interpret.

Comparisons between theoretical and empirical morphospaces usually point to the distinction that the axes of the latter are unstable, with the dimensions changing upon addition or subtraction of more taxa, but what is more seldom mentioned is a related consequence of ordinating a highdimensional space: the resulting axes represent a combination of many characters or parameters, making it difficult to understand what morphologies different parts of the ordinated space represent. In particular this restricts biologically meaningful interpretations of the morphospace, be they ecological, functional, or physiological (Wilson and Knoll 2010).

One widely used approach to understanding PCO axes highlights selected taxa using images (e.g., Swan and Saunders 1987, Fig. 1). Fig. 3 uses plot symbols generated from morphological character states to enrich the visualization of taxon distributions in the diatom

morphospace. We used the states of three characters describing the gross shape of the frustule to determine the form of the plot symbol (Fig. 3), showing a clear division between round and 
equant forms in the upper left and elongate forms, including raphe-bearing genera, in the lower right of the morphospace plot.

We can refine our interpretation of what PCO axes 1 and 2 represent by plotting the different states of characters most closely associated with those axes (Fig. 4). To choose characters for plotting, we used the results of the character-PCO axis association summarized in Figure 2 above to identify which characters contribute most to the first two PCO axes used to visualize the morphospace. Table 1 lists the characters with the strongest and most significant associations with PCO axes 1 and 2. Some of these characters are expected, particularly the shape of the structural pattern center of the primary silica ribs, because they are determinants both of overall morphology and of high-level taxonomy, and they thus reflect significant morphological variance. Other characters are more surprising, such as detailed features of the raphe or specialized processes, which apply to only a small subset of the genera in the analysis. A deeper statistical investigation would be needed to understand why characters we would expect a priori to be rather minor show such strong association with the first two PCO axes (though this might result from 'hitchhiking', associations between these traits and more significant traits found in the same clades). However, it is plausible that characters with few states and many missing entries are simply more likely to fall into concordant patterns on the PCO axes by chance alone, in a way that is not adequately corrected for in the calculation of $p$-values.

The different states of some of these characters most closely associated with PCO axes 1 and 2 are shown in Figure 4. This exercise divides the plot area into clearly defined diagonal quadrants (Figs. 4A-C). Figure 4A confirms the suggestion from Figure 3 that centric forms lie in the upper left half, and pennate forms in the lower right half of the plot. Figures $4 \mathrm{~B}-\mathrm{C}$, on the other hand, show an orthogonal division into forms with straight, clearly defined mantles in the 
upper right and forms with convex mantles without clear distinction from the valve face in the lower left.

The arrangement of character states in Figures 4D-G is less well defined, but still contributes meaning to the space defined by the two PCO axes shown. Diatoms with uniformly sized pores on the valve face occur all over the plot, while those with larger or smaller pores have positive PC 2 scores (Fig. 4D). Similarly, diatoms with unornamented rims are found all over the plot, while those with short marginal spinules mostly have positive PC 1 scores and those with long marginal spines mostly have positive PC 2 scores (Fig. 4E). Most of the forms with valve face pores in hexagonal arrangement have negative PC 1 scores, while those in square arrangement or in rows tend to have positive PC 1 scores (Fig. 4F). Finally, the convexity of the valve face seems to decrease with increasing PC 1 score (Fig. 4G). In summary, Figure 4 reveals the following tendencies in the PCO space: (1) straight and clearly defined mantles toward the upper right versus indistinct and convex mantles toward the lower left of the plot, and (2)

hexagonally-arranged pores and convex valve faces toward the left versus linearly-arranged pores and flatter valve faces toward the right of the plot.

Armed with a visualization of the morphospace and a better understanding of its axes, we can begin to investigate the diatoms' evolutionary history. There are two major records of evolutionary history: the fossil record and the record reconstructed from genetic information. While we focus on fossils in this paper, we begin by briefly exploring the morphospace from the perspective of molecular phylogeny.

\section{Morphospace and Molecular Data}

What relationship between molecular phylogeny and morphospace would we expect to see if the Cenozoic Era were characterized by the occupation of significant new morphospace; in 
other words, if our expectation of an untrended Cenozoic were false? If adding diversity were to add morphospace, we would see close relationships between the positions of genera on a tree and their position in morphospace, with derived clades occupying new and distinct regions. More specifically, having identified the evolution of raphids and the Thalassiosirales as key Cenozoic events, we might expect these groups to occupy discrete regions of morphospace.

By comparing the distribution of genera on a phylogenetic tree with their distribution on a morphospace plot, however, we can see that only the coarsest phylogenetic division is reflected in morphospace (Fig. 5). The tree topology shown is a molecular phylogeny by Sorhannus (2007), based on a maximum-likelihood analysis of SSU rRNA sequences. Other molecular phylogenies give broadly similar results, though the detailed arrangement of genera varies (e.g., Medlin and Kaczmarska 2004; Kooistra et al. 2007; for a review see Williams 2007). With the adjacent morphospace plots, the figure shows that pennates and centrics fall into different areas of morphospace (the lower right and upper left, respectively, as seen previously in Figs. 3 and 4), but groups at finer scales of phylogenetic resolution overlap. Within the pennates, for example, raphids and araphids fall in the same region; radial and bi- and multipolar centrics also overlap. It is important to note that of these four major groups highlighted in Fig. 5, only the raphids correspond to a clade. Clades within these groups do not occupy distinct regions to the exclusion of others; for example, the Thalassiosirales clade (Porosira through Cyclotella on the cladogram in Fig. 5, in various hues of blue/purple) do not fall in a distinct area within the bi- and multipolar centric group. This observation (which is not sensitive to the differences among phylogenies) suggests that beyond the establishment of centrics and pennates, clades generally re-evolved the same gross morphologies rather than explore new and distinct areas of morphospace. It also suggests, in terms of gross morphology, that we cannot reject our stationary hypothesis for 
morphospace occupancy after the radiation of pennate diatoms, based on the interpretation of molecular data.

The lack of distinction in morphospace between araphid and raphid diatoms makes sense if we consider the function and ecological significance of the raphe. Because it allows for gliding locomotion across surfaces, the raphid diatoms are highly successful in terrestrial habitats, and the evolution of the raphe in diatoms has thus been compared to the evolution of flight in birds in its significance (Sims et al. 2006). However, because Neptune is mainly a deep-sea record of open-ocean plankton, the raphe may in fact be of limited significance in this environment, regardless of its overall importance to the group. Thus we might actually expect raphid pennates in the plankton to occupy the same functional and ecological niches as the araphid pennates, and - if form and function are related - that they thus occupy the same regions of morphospace. The lack of correspondence between phylogeny and morphospace in Figure 5 might also be an artifact of the ordination of the morphospace. We have shown that much information is contained in higher PCO axes (Figs. 1 and 2), so we exercise caution in interpreting projected data directly. Fortunately, we can use the unordinated matrix of dissimilarities - i.e., the pairwise distances among genera in the full-dimensional space - to make a direct comparison with the phylogeny by calculating a comparable matrix of pairwise patristic distances (the sum of branch lengths, i.e., state changes along the branches, between two taxa) on the tree.

\section{A direct comparison of morphological to patristic distance is shown in Figure 6A; it} suggests very little correlation between the two. A simple linear regression of patristic distance on morphological distance has a squared correlation coefficient $\left(\mathrm{R}^{2}\right)$ value of 0.036 , suggesting at most a very weak positive correlation. To test the significance of this correlation between distance matrices (in which entries are dependent on one another) we performed a Mantel test 
(Sokal and Rohlf 1981: p. 813), a permutation test. With 1,000,000 iterations the test gives a 2sided $p$-value of 0.049 , suggesting that there is a marginally significant relationship between patristic molecular distance and morphological distance at the $95 \%$ confidence level; in any event, the $\mathrm{R}^{2}$ value suggests a weak correlation regardless of the $\mathrm{p}$-value.

Rather than using patristic distances (Fig. 6A), we can compare morphological distances to molecular distance directly, using the distance between aligned molecular sequences (i.e., identity) in the absence of a phylogenetic hypothesis (Fig. 6B). Using molecular distance directly removes the subjective choices necessary in selecting tree-building methods. The $\mathrm{R}^{2}$ in this case is only slightly higher, 0.057 . The Mantel test for this comparison suggests that this relationship is also more significant, with a $p$-value of 0.024 . If we accept these results, and if we assume that there is in fact an underlying positive relationship between morphology and molecular sequences, the somewhat surprising implication would be that phylogenetic treebuilding actually masks that signal, weakening the correlation between the two sets of distances. The qualitative sense provided by Figure 5 that the arrangement of taxa on the phylogenetic tree is not necessarily correlated with their arrangement in morphospace is thus confirmed quantitatively by a direct comparison of morphological distance to molecular distance. In summary, plotting phylogenetic relationships in morphospace suggests a weak relationship between morphology and descent. On the one hand, this is surprising, because diatom phylogenies predating the molecular era, and thus based on morphology, broadly agree with more recent molecular phylogenies. On the other hand, morphologically-based phylogenies rely on shared, derived features (synapomorphies) to signify inclusion in groups, while the data set underlying the morphospace consists of agnostically chosen, equally weighted (i.e., phenetic) characters. As such, we might not expect changes in the sequences coding for the ribosome to be 
correlated with frustule morphology, on which those sequences presumably have little direct bearing. Expected or not, the results of comparing phylogeny and morphospace suggest that different groups of diatoms, and subgroups within those groups, successively recolonized already-occupied regions of morphospace. Since the four major groups were already present by the earliest Cenozoic Era, the full extent of occupied morphospace should have been achieved early, and show little subsequent change. These results support the hypothesis that, in terms of disparity or morphological variety, the pattern across the Cenozoic Era was broadly stationary.

\section{Morphospace Through Time}

We now explore occupancy of the morphospace through the fossil record. When viewed

\section{as Cenozoic epochs in PCO axes 1 and 2, the occupied morphospace area seems, to a first}

approximation, to be relatively constant through time (colored polygons at the bottom of Fig. 7).

Comment [BK7]: Fig. 7 here

The area occupied appears to expand slightly to the lower right and upper left by the Miocene, and the Oligocene area is expanded to the extreme upper right, but this is due to a single taxon with an unusual morphology (see point between "O" and "l" of "Oligocene"). In addition to the slight expansion of morphospace area, sparsely occupied areas appear to become "filled in" and more densely occupied through time.

The Cretaceous time bins, particularly the Early Cretaceous, appear to occupy a much smaller area of morphospace. However, rigorously interpreting the Cretaceous results is challenging because so much less data was included for these intervals. Specifically, the Early and Late Cretaceous time bins contain taxon lists from one and three ODP holes respectively, while the Paleocene alone contains lists from 61 samples from six ODP holes. Furthermore, several morphologically divergent taxa did not meet the applied culling threshold, due to incomplete descriptions, and were excluded from the analysis. The Cretaceous samples may thus 
show less morphological variety than was actually present, although it was probably still lower than the Cenozoic samples, particularly for the Early Cretaceous.

There are many ways to quantify disparity, or what has been called the "within-group variance of form" (Erwin 2007), that go beyond the qualitative description of morphospace occupancy provided by plots like Figure 7. These include counts of higher taxa, the sum of univariate variances, total range, the number of unique pairwise character combinations, participation ratio, various measures of $\mathrm{PCO}$ volume, and mean pairwise distance (for details, see Thomas and Reif 1993; Foote 1995a; Ciampaglio et al. 2001; Erwin 2007). As explained below, some of these metrics may describe different aspects of morphospace occupation; two major facets are how far taxa are from each other, on average, and what volume of the space is occupied. Next, we present metrics for those two aspects, using mean pairwise distance to describe the former, and two measures of occupied PCO volume (convex hull and alpha shape volume) to describe the latter.

Mean pairwise distance is a commonly used metric for disparity (for example, by Foote 1995a; Lupia 1999; Boyce and Knoll 2002), having the advantage that it can be calculated from the morphological data directly without requiring ordination. Another advantage of this metric is that it has been shown to be relatively insensitive to sampling bias (Foote 1995a; Ciampaglio et al. 2001; Deline 2009). Mean pairwise distance suggests that disparity changed little over the course of the Cenozoic Era (Fig. 8A). These results show that pairs of genera are, on average, about $70-75 \%$ similar in applicable characters, with an apparent peak in the Oligocene and declining gradually over the course of the Cenozoic Era. A disadvantage of this method is that is says nothing about the total extent or shape of the occupied morphospace.

Calculating convex hull volume, another disparity metric, is a way of quantifying the amount of space occupied by a set of points (Foote 1999). A convex hull is a shape that encloses 
a set of points using the smallest possible number of those points (in two dimensions, it is the equivalent of spanning a rubber band around a set of pegs). The volume (or hypervolume) of this shape for each time bin was calculated for increasing numbers of PCO axes, up to 10 (beyond which computational limits are reached). In order to be comparable, the results have been standardized to the largest value in the time series.

The convex hull volumes calculated are shown in Figure 8B. The plot shows an increase in volume with time, regardless of the number of dimensions used to calculate it. There is a decline in volume over the most recent 5 Myr or so; however, this may be related to the wellknown edge effect of the range-through taxon counting method (Raup 1972; Alroy 2010). The largest volume is reached in the Oligocene, showing a particularly pronounced spike in the $29 \mathrm{Ma}$ time bin. However, by examining the Oligocene time slice plotted in Figure 7, it is clear that this spike is due to a single outlier taxon present only at that time. This illustrates a shortcoming of the convex hull method: due to outliers or widely separated clusters of points, it can include substantial areas of unoccupied space.

Alpha shapes are a generalization of convex hulls that, when appropriate values of $\alpha$ are chosen, address the empty-space problem of convex hulls. Alpha shapes (Edelsbrunner and Mücke 1992) allow unoccupied space to be removed from the convex hull, akin to "scooping out" space between points with an ice-cream scoop of a given radius, $\alpha$. As the value of $\alpha$ increases, the alpha shape converges on the convex hull; as the value approaches zero, the alpha shape collapses to set of points itself (disconnected shapes where each shape is simply one of the points of the point set). The method was first applied to morphospaces by Low (2006); detailed treatments of the algorithm to calculate alpha shape volumes can be found in Edelsbrunner and Mücke (1994) and Da and Yvinec (2000). We used the alphashape3d package in $R$ (Lafarge and Pateiro-Lopez 2012); it is limited to calculating volume in three dimensions. We visualized the 
alpha shapes enclosing points in 3D space for each time bin and many values of $\alpha$; from this, we selected by inspection the value of $\alpha$ that best enclosed the point clouds without either enclosing too much unoccupied space or disjointing the alpha shape across all time bins. We thus broadly followed the methodology of Low (2006), except that we chose a single value of $\alpha$ across all time bins rather than selecting different values for each (providing, in our opinion, a more evenhanded comparison across time bins). From this exercise we find that the morphospace occupation shows the same pattern of secular increase in volume as the convex hull volume, but without the exaggerated peaks (Fig. 8C). Alpha shape volume roughly doubles over the Cenozoic Era.

These different metrics of disparity — mean pairwise distance and the volume of morphospace occupied — give very different results because they measure different aspects of disparity. Mean pairwise distance declines slightly over the Cenozoic Era, in stark contrast to occupied volume (as calculated either by convex hulls or by alpha shapes), which increases substantially over time. These divergent results can be understood as measuring two different aspects of morphospace occupation. The volume increases as the extent of morphospace occupied increases. If the number of genera were to stay constant, we would also expect a concomitant increase in average pairwise distance. However, the number of genera occupying this space also increases through time, leaving genera packed more tightly into morphospace and thus reducing the average distance between them. Disparity can thus both increase substantially and decrease slightly over the Cenozoic Era - the former in the sense of the range of morphological variety, and the latter in the sense of the average morphological distinctness of taxa.

Another way to quantify the "packing" of morphospace suggested by the decline in mean pairwise distance is to calculate the total volume occupied divided by the number of genera. This 
result is shown in Figure 8D and it shows a similar trend to the mean pairwise distance results in

Figure 8A: the amount of PCO volume per genus decreases slightly through time, again suggesting that the increase in the number of taxa filling morphospace outpaced the growth of the volume occupied.

It is worth noting here that the observed phenomenon of taxa "packing" into morphospace - while geometrically explained by differing rates of change in morphospace volume and genus richness—need not necessarily imply an underlying evolutionary process or causal mechanism constraining (i.e. "packing", in a more loaded sense) taxa into a particular morphospace volume. Several such mechanisms have been proposed to explain the discordance between taxonomic and morphological diversification, for example, the entrenchment of developmental systems (e.g. Erwin 1994) or the saturation of ecospace (e.g. Valentine 1969). However, before attributing observed patterns to underlying processes, it is worth considering what a "null" expectation for a diversifying clade might be in terms of morphospace occupation. for example, the pattern that might result from random-walk-type processes. Several mathematical models have been developed to explore such an expectation. Depending on both the model and parameters chosen, these models can produce the oft-observed pattern of rapid early morphological diversification (and its subsequent outpacing by taxonomic diversification) as a result of speciation and extinction within the geometry of morphospace, "diffusive" evolution, or branching random walks, without requiring special explanation (Foote 1996,

Gavrilets 1999, Pie and Weitz 2005).

It is also worth considering that the "packing" of morphospace, observed as a decrease in the ratio of volume occupied to genus richness, could also result from sampling differences. If genus richness were less sensitive to sampling bias than volume occupied, then a secular increase in sampling could result in genus richness growing more quickly than volume - producing the 
observed pattern as a result of sampling alone. We explore the effects of sampling on our results

615 in the companion paper in this volume.

Because the higher PCO axes contain substantial information (Figs. 1 and 2), we noted

617 that results based only on a few ordinated axes should be interpreted with caution. In order to

618 examine morphospace occupancy in a more direct way, we counted the number of realized

619 character states through time, considering the raw morphological data without ordination. This

620 metric is similar to the number of realized unique pairwise character combinations of Thomas

621 and Reif (1993) and Foote (1995a), and is of a lower dimensionality than the extremely sparsely

622 populated full morphospace. However, it considers only whether a character state is realized,

623 independent of other characters. In morphospace studies with relatively few characters, the

624 former approach is preferable because the 1-dimensional space of character states can quickly

625 become saturated (i.e., all character states are, more or less, always realized, but occur in

626 different combinations in different taxa). In the present study, however, the space of character

627 states only approaches saturation at the very end of the time series (Fig. 9A), and it therefore has sufficient sensitivity to render pairwise comparisons unnecessary.

Figure 9A shows that the number of realized character states increases through time, the Cenozoic Era. We interpret this to mean that as new taxa evolved in the Cenozoic Era, they increasingly showed new combinations of existing character states over newly evolved states, even as new states continued to evolve. Another way to understand this result is to consider it as 
the slight decline in the mean pairwise distance result shown in Figure 8A. The concordance of these two sets of results from ordinated and unordinated morphospace data (PCO volume occupied agreeing with number of realized states, and mean pairwise distance agreeing with pergenus realized states) lends confidence to our interpretations from ordinated data.

\section{A final aspect to consider concerns the increase in sampling intensity over the Cenozoic}

Era, which casts doubt on the reliability of the observed increases in morphospace occupation over that time period (Fig. 10). The roughly exponential increase in sampling raises the question are real or result from sampling biases. The importance of secular variation in sampling intensity is well established in studies of taxonomic diversity through time (e.g., Alroy et al. 2001), where sampling biases have been shown to (1) greatly attenuate patterns of diversity increase, and (2) shift the timing of peaks, or even reverse patterns (reviewed by Alroy 2010). The Neptune record has been widely cited as the canonical compilation for diatom diversity, but its uneven sampling has been identified and attempts at correcting for it have been made by applying sampling standardization methods (Rabosky and Sorhannus 2009). We tend to think morphospaces and studies of morphological disparity constitute a window to evolutionary history that is independent of taxonomic diversity, and this may, in part, explain why sampling biases have often not been considered (see, however, Foote 1995a; Ciampaglio et al. 2001; Shen et al. 2008; Deline 2009). While two data sets of taxonomic diversity and morphological disparity do indeed offer different information, both are subject to the same underlying sampling biases. These biases are considered in more detail in the companion paper in this issue.

\section{Conclusions}



morphological characters of the taxa they represent. This alternative to plotting generic symbols, like dots or crosses, or labeling selected points with images, goes some way towards correcting the shortcoming of many empirical morphospaces that lack clear identification of what their axes mean.

Plotting phylogenetic relationships onto diatom morphospace suggests very little relationship between morphology and descent; this implies that the same regions of morphospace

668 were iteratively colonized by different clades. Thalassiosirales and raphid pennates — clades that evolved in the Cenozoic Era-do not appear to occupy regions of morphospace distinct from the clades within which they arose. From the phylogenetic perspective, then, most of the extent of diatom morphospace seems to have been occupied early, suggesting that the Cenozoic Era was untrended in terms of disparity, or morphological variety.

We examined changes in Cenozoic diatom morphospace occupation through time using the Neptune database, based on the marine fossil record, and calculated disparity in each time slice. Two sets of disparity metrics show different secular trends, which we argue is a consequence of the fact that they measure different aspects of disparity.

The "packing" of morphospace, or how much morphospace on average separates taxa, can be measured using mean pairwise distance, the per-genus alpha shape volume, or the pergenus number of realized character states. The last shows a decreasing trend, while the first two show only a slight decline through the Cenozoic Era, varying somewhat with the choice of the $\alpha$ parameter.

The volume of morphospace occupied, delimited by convex hulls or alpha shapes (the latter are less distorted by outliers) and the number of realized character states are proxies for the total volume or amount of morphospace occupied. These metrics both show an increase through 
the Cenozoic Era. Taken together, they show an increase in the total extent of occupied morphospace, with an associated increase in the number of taxa keeping pace with the rate of space expansion, which leads to stationary or even increasing "packing” of taxa through Cenozoic time.

A number of lines of evidence, then, point to stationary disparity through the Cenozoic Era: mean pairwise distance, alpha volume per genus, and the phylogenetic view of morphospace. In contrast, measures of the total extent of occupied morphospace, when viewed independently, suggest an increase through time. We suspect, however, that the latter are affected by sampling bias, as suggested by a corresponding increase in the number of taxa in the morphospace analysis and the number of taxonomic lists in the Neptune database.

Since mean pairwise distance has been shown to be relatively insensitive to sampling bias, we believe that our results point toward unchanging Cenozoic morphospace occupation.

This conclusion can be further substantiated by applying sampling-standardization methods, such as those developed for studies of taxonomic diversity, to diatom morphospace.

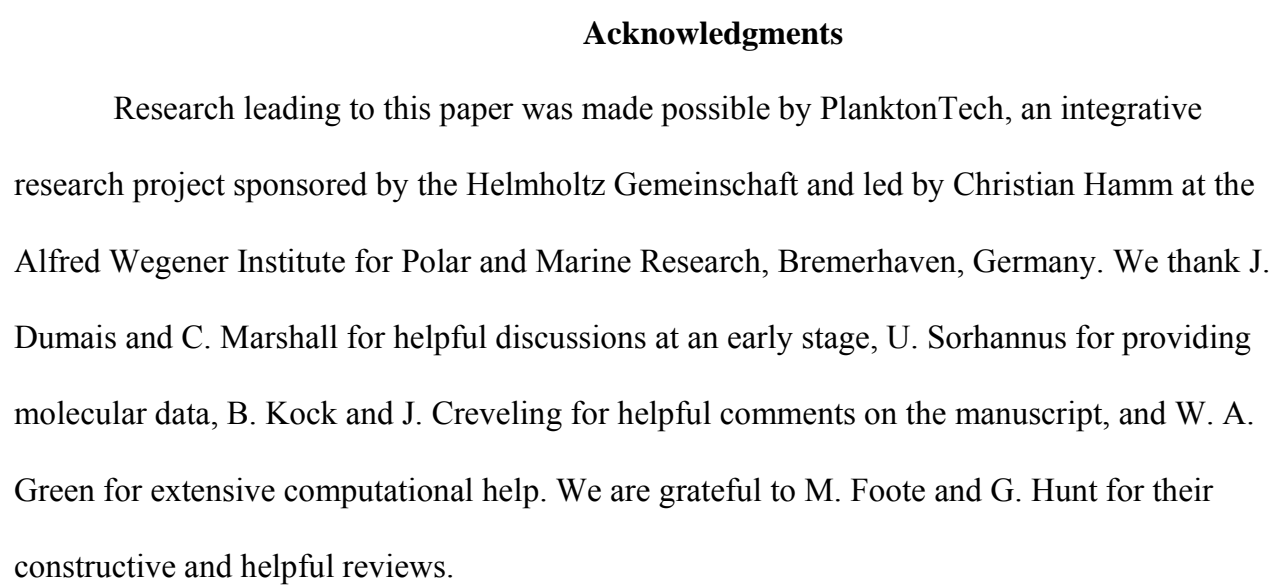
research project sponsored by the Helmholtz Gemeinschaft and led by Christian Hamm at the Alfred Wegener Institute for Polar and Marine Research, Bremerhaven, Germany. We thank J. Dumais and C. Marshall for helpful discussions at an early stage, U. Sorhannus for providing molecular data, B. Kock and J. Creveling for helpful comments on the manuscript, and W. A. Green for extensive computational help. We are grateful to M. Foote and G. Hunt for their constructive and helpful reviews. 
Kotrc and Knoll 32

\section{Literature Cited}

Alroy, J. 2010. Fair sampling of taxonomic richness and unbiased estimation of origination and extinction rates. In J. Alroy and G. Hunt, eds., Quantitative Methods in Paleobiology, Paleontological Society Papers, 16:55-80.

Alroy, J., C. R. Marshall, R. K. Bambach, K. Bezusko, M. Foote, F. T. Fürsich, T. A. Hansen, S. M. Holland, L. C. Ivany, D. Jablonski, et al. 2001. Effects of sampling standardization on estimates of Phanerozoic marine diversification. Proceedings of the National Academy of Sciences 98:6261.

Anderson, B. M., D. Pisani, A. I. Miller, and K. J. Peterson. 2011. The environmental affinities of marine higher taxa and possible biases in their first appearances in the fossil record. Geology 39:971-974.

Anonymous. 1962. Report of the Systematics Association committee for descriptive biological terminology, II and IIa. Terminology of simple symmetrical plane shapes (Charts 1, 1a). Taxon 11:145-156.

Anonymous. 1975. Proposals for a standardization of diatom terminology and diagnoses. Beihefte zur Nova Hedwigia 53:323-354.

Barber, H. G. and E. Y. Haworth. 1981. A guide to the morphology of the diatom frustule: with a key to the British freshwater genera. Freshwater Biological Association.

Barron, J. A. 1985. Miocene to Holocene planktic diatoms. In H. Bolli, J. Saunders, and K. Perch-Nielsen, eds., Plankton Stratigraphy, 713-762. Cambridge University Press, Cambridge, U.K.

Boyce, C. K. and A. H. Knoll. 2002. Evolution of developmental potential and the multiple independent origins of leaves in Paleozoic vascular plants. Paleobiology 28:70. 
Chacón-Baca, E., H. Beraldi-Campesi, S. R. S. Cevallos-Ferriz, A. H. Knoll, and S. Golubic. 2002. 70 Ma nonmarine diatoms from northern Mexico. Geology 30:279.

Chang, K. H., K. Suzuki, S. O. Park, K. Ishida, and K. Uno. 2003. Recent advances in the Cretaceous stratigraphy of Korea. Journal of Asian Earth Sciences 21:937-948.

Ciampaglio, C. N., M. Kemp, and D. W. McShea. 2001. Detecting changes in morphospace occupation patterns in the fossil record: characterization and analysis of measures of disparity. Paleobiology 27:695-715.

Da, T. K. F. and Yvinec M. 2000. 3D Alpha Shapes. In CGAL User and Reference Manual. CGAL Editorial Board, 4.4 edition. Accessed online 5/16/2014 at http://doc.cgal.org/latest/Alpha_shapes_3/index.html\#Chapter_3D_Alpha_Shapes

Damsté, J. S. S., G. Muyzer, B. Abbas, S. W. Rampen, G. Massé, W. G. Allard, S. T. Belt, J. M. Robert, S. J. Rowland, J. M. Moldowan, et al. 2004. The rise of the rhizosolenid diatoms. Science 304:584-587.

Deline, B. 2009. The effects of rarity and abundance distributions on measurements of local morphological disparity. Paleobiology 35:175-189.

Du Buf, H. and M. M. Bayer. 2002. Automatic Diatom Identification, Series in Machine Perception and Artificial Intelligence, vol. 51. World Scientific, Singapore.

Dudley, R. and C. Gans. 1991. A critique of symmorphosis and optimality models in physiology. Physiological Zoology 64:627-637.

Dugdale, R. C. and F. P. Wilkerson. 1998. Silicate regulation of new production in the equatorial Pacific upwelling. Nature 391:270-273.

Eble, G. 2000. Contrasting evolutionary flexibility in sister groups: disparity and diversity in Mesozoic atelostomate echinoids. Paleobiology 26:56-079. 
Edelsbrunner, H. and E. P. Mücke. 1992. Three-dimensional alpha shapes. In Proceedings of the 1992 Workshop on Volume Visualization, 75-82. ACM.

Edelsbrunner, H. and E. P. Mücke. 1994. Three-dimensional alpha shapes. ACM Transactions on Graphics 13(1):43-72.

Erwin, D. H. Early introduction of major morphological innovations. Acta Palaeontological Polonica 38(3/4):281-294.

Erwin, D. H. 2007. Disparity: morphological pattern and developmental context. Palaeontology 50:57-73.

Erwin, D. H., M. Laflamme, S. M. Tweedt, E. A. Sperling, D. Pisani, and K. J. Peterson. 2011. The Cambrian conundrum: Early divergence and later ecological success in the early history of animals. Science 334:1091-1097.

Falkowski, P. G., M. E. Katz, A. H. Knoll, A. Quigg, J. A. Raven, O. Schofield, and F. J. R. Taylor. 2004. The Evolution of Modern Eukaryotic Phytoplankton. Science 305:354-360.

Fenner, J. 1985. Late Cretaceous to Oligocene planktic diatoms. In H. Bolli, J. Saunders, and K. Perch-Nielsen, eds., Plankton Stratigraphy, 713-762. Cambridge University Press, Cambridge, U.K.

Foote, M. 1993. Discordance and concordance between morphological and taxonomic diversity. Paleobiology 19:185-204.

1995 a. Morphological diversification of Paleozoic crinoids. Paleobiology 21:273-299. 1995 b. Morphology of Carboniferous and Permian crinoids. Contributions from the Museum of Paleontology, University of Michigan 29:135-184.

. 1996. Models of Morphological Diversification. In D. Jablonski, D. H. Erwin and J. H. Lipps, eds., Evolutionary paleobiology: in honor of James W. Valentine, 62-88. 
1997. The evolution of morphological diversity. Annual Review of Ecology and Systematics 28:129-152.

1999. Morphological diversity in the evolutionary radiation of Paleozoic and postPaleozoic crinoids. Paleobiology 25:1-116.

Fourtanier, E. 1991. Diatom biostratigraphy of equatorial Indian Ocean Site 758. Ocean Drilling Program Scientific Results 121:189-208.

Gavrilets, S. 1999. Dynamics of clade diversification on the morphological hypercube. Proc. R. Soc. Lond. B 266:817-824.

Gersonde, R. and D. M. Harwood. 1990. Lower Cretaceous diatoms from ODP Leg 113 Site 693 (Weddell Sea). Part 1: Vegetative cells. Proceedings of the Ocean Drilling Program, Scientific Results 113:365-402.

Gould, S. J. 1989. Wonderful Life: The Burgess Shale and the Nature of History. W.W. Norton.

Gower, J. C. 1966. Some distance properties of latent root and vector methods used in multivariate analysis. Biometrika 53:325-338.

Hajós, M. 1976. Upper Eocene and Lower Oligocene Diatomaceae, Archaeomodaceae, and Silicoflagellatae in Southwestern Pacific sediments. Initial Reports of the Deep Sea Drilling Project 35:817-883.

Hajós, M. and H. Stradner. 1975. Late Cretaceous Archaeomonadaceae, Diatomaceae, and Silicoflagellatae from the South Pacific Ocean, Deep Sea Drilling Project, Leg 29, Site 275. Initial Reports of the Deep Sea Drilling Project 29:913-1009.

Hamm, C. and V. Smetacek. 2007. Armor: Why, When, and How. In P. G. Falkowski and A. H. Knoll, eds., Evolution of Primary Producers in the Sea. Elsevier, Burlington, MA. 
Hamm, C., R. Merkel, O. Springer, P. Jurkojc, C. Maier, K. Prechtel, and V. Smetacek. 2003. Architecture and material properties of diatom shells provide effective mechanical protection. Nature 421:841-843.

Hargraves, P. E. 1986. The relationship of some fossil diatom genera to resting spores. In M. Ricard, ed., Proc. 8th Int. Diatom Symp., Paris, Aug. 1984, 27:67-80. Koeltz Scientific, Königstein, Germany.

Harper, H. E. and A. H. Knoll. 1975. Silica, diatoms, and Cenozoic radiolarian evolution. Geology 3:175-177.

Harwood, D. M. 1988. Upper Cretaceous and lower Paleocene diatom and silicoflagellate biostratigraphy of Seymour Island, eastern Antarctic Peninsula. Geological Society of America.

Harwood, D. M., V.A. Nikolaev, and D. M. Winter. 2007. Cretaceous records of diatom evolution, radiation, and expansion. In S. W. Starratt, ed., Pond scum to carbon sink: Geological and environmental applications of the diatoms, Paleontological Society Papers, 13:33-59. The Paleontological Society.

Hendey, N. I. and R. Simonsen. 1972. Muelleriella limbata (Ehrenberg) Van Heurck in Eocene South Atlantic Cores. Nova Hedwigia 39:79-94.

Kooistra, W., R. Gersonde, L. K. Medlin, and D. G. Mann. 2007. The origin and evolution of the diatoms: their adaptation to a planktonic existence. In P. G. Falkowski and A. H. Knoll, eds., Evolution of Primary Producers in the Sea. Elsevier, Boston.

Kooistra, W. H. C. F. and L. Medlin. 1996. Evolution of the diatoms (Bacillariophyta) IV: A reconstruction of their age from small subunit rRNA coding regions and fossil record. Molecular Phylogenetics and evolution 6:391-407. 
Lafarge, T. and B. Pateiro-Lopez. 2012. alphashape3d: Implementation of the 3D alpha-shape for the reconstruction of $3 \mathrm{D}$ sets from a point cloud. R package version 1.0.

Lazarus, D. B. 1994. Neptune: a marine micropaleontology database. Mathematical Geology $26: 817-832$.

Lazarus, D. B., B. Kotrc, G. Wulf, and D. N. Schmidt. 2009. Radiolarians decreased silicification as an evolutionary response to reduced Cenozoic ocean silica availability. Proceedings of the National Academy of Sciences 106:9333.

Lazarus, D. B., J. Barron, J. Renaudie, P. Diver, and A. Türke. 2014. Cenozoic Planktonic Marine Diatom Diversity and Correlation to Climate Change. PLoS ONE 9(1): e84857. doi:10.1371/journal.pone.0084857

Low, S. L. 2006. Quantifying the morphological evolution of the Nautiloidea through the Phanerozoic. Ph.D. thesis, Harvard University.

Lupia, R. 1999. Discordant morphological disparity and taxonomic diversity during the Cretaceous angiosperm radiation: North American pollen record. Paleobiology 25:1-28.

Marshall, C. R. 2003. Nomothetism and understanding the Cambrian "explosion". Palaios 18:195-196.

Marx, F. G. and M. D. Uhen. 2010. Climate, critters, and cetaceans: Cenozoic drivers of the evolution of modern whales. Science 327:993-996.

McGhee, G. R. 1999. Theoretical morphology: the concept and its applications. Columbia University Press.

Medlin, L. K. and I. Kaczmarska. 2004. Evolution of the diatoms: V. Morphological and cytological support for the major clades and a taxonomic revision. Phycologia 43:245270. 
Meyer, D., A. Zeileis, and K. Hornik. 2011. ved: Visualizing Categorical Data. R package version 1.2-12.

Niklas, K. J. 2004. Computer models of early land plant evolution. Annual Review of Earth and Planetary Sciences 32:47-66.

Pantocsek, J. 1886. Beiträge Zur Kenntniss Der Fossilen Bacillarien Ungarns, vol. 1. Buchdruckerei von Julius Platzko.

Pappas, J. L. 2005. Theoretical morphospace and its relation to freshwater GomphonemoidCymbelloid diatom (Bacillariophyta) lineages. Journal of Biological Systems 13:385-398.

Pie, M. R. and J. S. Weitz. 2005. A Null Model of Morphospace Occupation. The American Naturalist $166(1): E 1-E 13$

R Development Core Team. 2011. R: A Language and Environment for Statistical Computing. R Foundation for Statistical Computing, Vienna, Austria.

Rabosky, D. L. and U. Sorhannus. 2009. Diversity dynamics of marine planktonic diatoms across the Cenozoic. Nature 457:183-186.

Raup, D. M. 1972. Taxonomic diversity during the Phanerozoic. Science 177:1065-1071.

Raup, D. M. and A. Michelson. 1965. Theoretical morphology of the coiled shell. Science 147:1294-1295.

Raven, J. A. 1997. The vacuole: A cost-benefit analysis. Advances in Botanical Research 25:5986.

Raven, J. A. and A. M. Waite. 2004. The evolution of silicification in diatoms: inescapable sinking and sinking as escape? New Phytologist 162:45-61.

Rothpletz, A. 1896. Ueber die Flysch-Fucoiden und einige andere fossile Algen, sowie über liasische Diatomeen führende Hornschwämme. Zeitschrift der Deutschen Geologischen Gesellschaft 48:854-914. 
Round, F. E., R. M. Crawford, and D. G. Mann. 1990. The Diatoms: biology \& morphology of the genera. Cambridge University Press.

Shen, B., L. Dong, S. Xiao, and M. Kowalewski. 2008. The Avalon explosion: evolution of Ediacara morphospace. Science 319:81.

Siegel, S. and N. J. Castellan Jr. 1988. Nonparametric Statistics for the Behavioral Sciences. McGraw Hill, 2 ed.

Sims, P. A., D. G. Mann, and L. K. Medlin. 2006. Evolution of the diatoms: insights from fossil, biological and molecular data. Phycologia 45:361-402.

Small, J. 1946. Quantitative evolution: Numerical analysis of tables to illustrate the geological history of species number in diatoms; an introductory summary. In Proceedings of the Royal Irish Academy. Section B: Biological, Geological, and Chemical Science, 51:5380.

Smetacek, V. 1999. Diatoms and the ocean carbon cycle. Protist 150:25-32. 2001. A watery arms race. Nature 411:745-745.

Smith, L. H. and P. M. Bunje. 1999. Morphologic diversity of inarticulate brachiopods through the Phanerozoic. Paleobiology 396-408.

Sokal, R. R. and F. J. Rohlf. 1981. Biometry: the principles and practice of statistics in biological research. WH Freeman New York, 3rd ed.

Sorhannus, U. 2004. Diatom phylogenetics inferred based on direct optimization of nuclearencoded SSU rRNA sequences. Cladistics 20:487-497.

- 2007. A nuclear-encoded small-subunit ribosomal RNA timescale for diatom evolution. Marine Micropaleontology 65:1-12.

Spencer-Cervato, C. 1999. The Cenozoic deep sea microfossil record: explorations of the DSDP/ODP sample set using the Neptune database. Palaeontologia Electronica 2. 
Sperling, E. A., D. Pisani, and K. J. Peterson. 2011. Molecular paleobiological insights into the origin of the brachiopoda. Evolution \& Development 13:290-303.

Stevens, S. S. 1946. On the theory of scales of measurement. Science 103:677-680.

Suto, I. 2004. Taxonomy of the diatom resting spore form genus Liradiscus Greville and its stratigraphic significance. Micropaleontology 50:59-79. 2005. Observations on the fossil resting spore morphogenus Peripteropsis gen. nov. of the marine diatom genus Chaetoceros (Bacillariophyceae) in the Norwegian Sea. Phycologia 44:294-304.

Suto, I., R. W. Jordan, and M. Watanabe. 2009. Taxonomy of middle Eocene diatom resting spores and their allied taxa from the central Arctic Basin. Micropaleontology 55:259-312.

Suto, I., M. Watanabe, and R. W. Jordan. 2011. Taxonomy of the fossil marine diatom resting spore genus Odontotropis. Diatom Research 26:255-272.

Swan, A. R. H. and W. B. Saunders. 1987. Function and shape in late Paleozoic (midCarboniferous) ammonoids. Paleobiology 297-311.

Thomas, R. D. K. and W. E. Reif. 1993. The skeleton space: a finite set of organic designs. Evolution 341-360.

Valentine, J. W. 1969. Patterns of taxonomic and ecological structure of the shelf benthos during Phanerozoic time. Palaeontology 12(4):684-709.

Webster, M. 2007. A Cambrian peak in morphological variation within trilobite species. Science $317: 499-502$.

Williams, D. M. 2007. Diatom phylogeny: Fossils, molecules and the extinction of evidence. Comptes Rendus Palevol 6:505-514.

Wilson, J. P. and A. H. Knoll. 2010. A physiologically explicit morphospace for tracheid-based water transport in modern and extinct seed plants. Paleobiology 36:335-355. 
Kotrc and Knoll 41

919 Witt, O. N. 1886. Über den Polierschiefer von Archangelsk-Kurojedowo im Gouv. Simbirsk. Verhandlungen der Russisch-Kaiserlichen Mineralogischen Gesellschaft zu St Petersburg 2:137-177.

922 


\section{Figure captions}

Figure 1: [one-column, print B\&W] Plots showing the distribution of variance among the principal coordinate axes. A, the magnitude of eigenvalues associated with the PCO axes, which is indicative of their relative information content. Although the higher eigenvalues account for much of the total, suggesting that much of the information is contained in them, the first two PCO axes do have much larger associated eigenvalues, and the inclusion of further axes shows rapidly diminishing returns. $B$, the squared correlation $\left(\mathrm{R}^{2}\right)$ between squared pairwise dissimilarities in the original $(\mathrm{m} \times \mathrm{m})$ matrix and squared Euclidean distances in a PCO-space $(\mathrm{y}$ axis) including increasing numbers of PCO axes (x-axis).

Figure 2: [full page, print $\mathrm{B} \& \mathrm{~W}$ ] The degree of association between PCO axes (x-axis) and characters in the morphospace (y-axis). Circle diameter is proportional to the Cramér coefficient (from zero to one, zero suggesting the PCO score is independent of character state). Circle color indicates the associated $p$-value, darker meaning more significant. Comparisons with $p$-values $>0.05$ were not plotted and were disregarded in marginal row and column sums.

Figure 3: [two-column, print B\&W, color online] Morphospace plot of the first two PCO axes, with plot symbols generated from gross shape character states. The shape of the plot symbolellipse, rectangle, triangle, or oval-represents character 1 (the valve view outline shape category). The aspect ratio of the plot symbol represents character 2 (the aspect ratio of the diatom frustule in valve view). Character 90 (presence or absence of a raphe) is represented by a vertical line drawn within the plot symbol. 
947 Figure 4: [one-column, print B\&W, color online] Morphospace plots of the first two PCO axes, 948 with plot symbols denoting character states for seven of the characters (A-G, character numbers shown in parentheses, see online supplement for detailed description) most associated with those axes (see Table 1 and Fig. 2).

Figure 5: [full page, print color] Left, topology of a molecular phylogeny of diatoms (Sorhannus 2007) based on a maximum likelihood analysis of nuclear-encoded SSU rRNA sequences, trimmed to show only representative species from each of the 44 genera found both in the phylogeny and this study. The four plots on the right show where the genera in each of the four major groups fall in the morphospace (PCO axes 1 and 2, plot area as in Figs. 3, 4, \& 5.) Within each of the four groups, genera are color-coded by proximity on the tree, e.g., in the top panel, the taxa colored red form a subclade within the raphids.

Figure 6: [one-column, print B\&W, B\&W online] A, Pairwise morphological distances (character state mismatches divided by number of possible matches) plotted against patristic distance on the tree shown in Figure 5. B, Pairwise morphological distances plotted against pairwise molecular distance (identity between aligned sequences, calculated using the function dist.alignment() from the R package seqinr).

Figure 7: [one- or two column, print color] Morphospace, as represented by the first two PCO axes, resolved through time using range-through taxon counting of Neptune occurrences. The colored polygons at the bottom of the plot are convex hulls enclosing the taxa present at each time bin, labeled in the corresponding colors. 
971 Figure 8: [two-column, print B\&W, color online] Metrics of morphological disparity (A-D) and

972 diversity (E) through time, using Neptune occurrences under range-through taxon counting. A,

973 Mean pairwise dissimilarity between genera, as character state mismatches divided by number of possible matches. B, Convex hull (hyper-)volume containing genera, normalized to largest value; black line is volume calculated over the first three PCO axes, grey lines are volume over the first four, five, etc. up to ten PCO axes. C, Alpha shape volume containing genera; black line is volume for $\alpha$-value chosen by inspection to best capture occupied volume across time bins, grey lines are other $\alpha$-values. $\alpha=10$ recovers the convex hull solution. D, Alpha shape volume (as in C) divided by number of genera. E, Species-level diversity from Neptune database (includes genera left out of morphospace analysis) in black; genus-level diversity in morphospace analysis in grey. Error bars not shown; please see Figures 7-9 of the companion paper in this volume for analysis and discussion of possible sources of error in these results.

Figure 9: [two-column, print B\&W, color online] Number of morphological character states observed through time. A, Number of realized states (mean of 1,000 bootstrap replicates, error bars show one standard error on either side of the mean). B, Number of states (as in A) divided by the number of genera (as in Fig. 8E). The total number of states in the (culled) morphological data matrix used in the analysis is 317.

Figure 10: [one-column, print B\&W, color online] Number of taxonomic lists (i.e., described samples) per time bin in the Neptune database. Sampling increases approximately exponentially with time. 
A

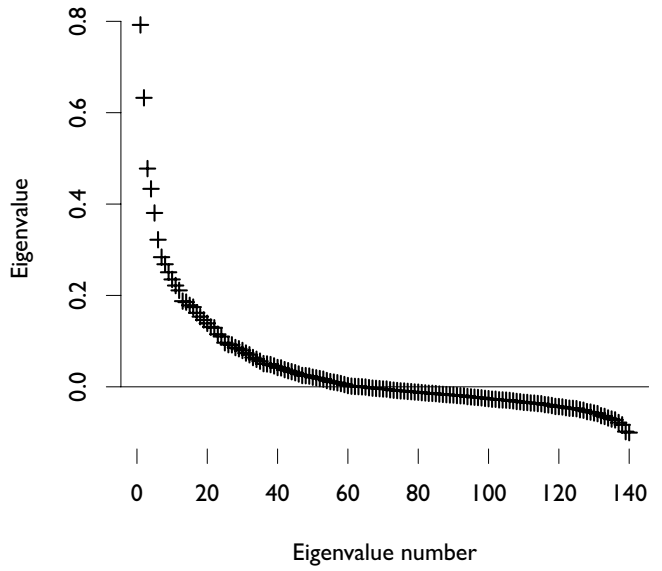

B

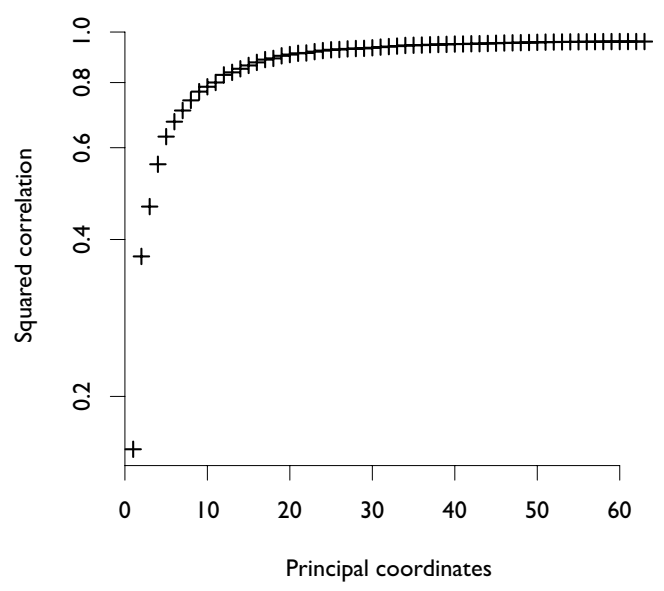




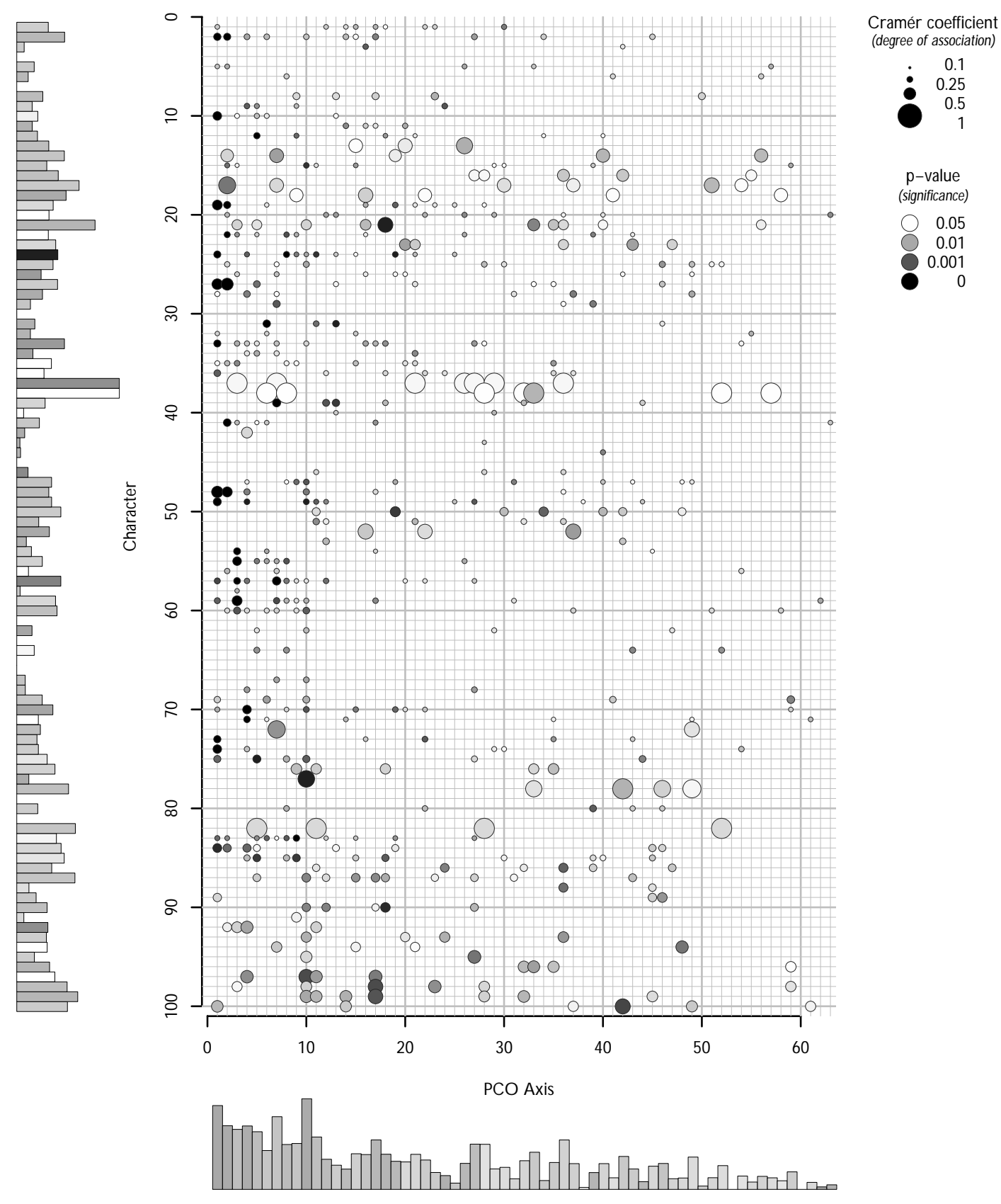




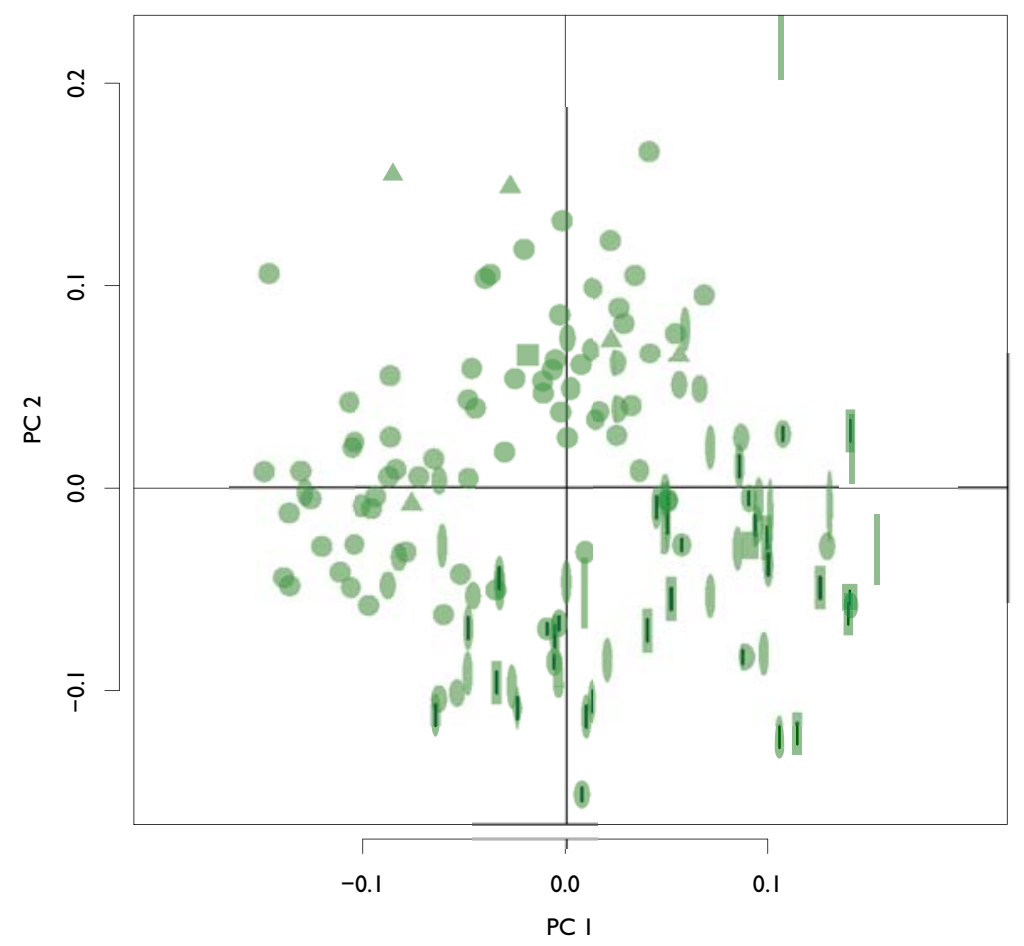

Outline shape in valve view (I)

- Elliptical

- Rectangular

- Rhombic

Ovate

A Triangular

Aspect ratio in valve view (2)

Linearis

| Anguste

Anguste late

Late

(- $1: t$

1. Latissime

D Depresse

Perdepresse

Raphe (90)

Rophe absent

Raphe present 


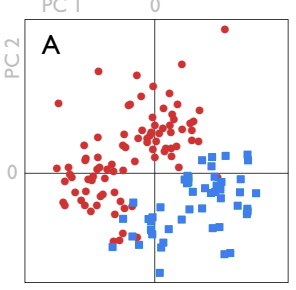

Shape of structural pattern center (48)

- Ring-shaped (annulus)
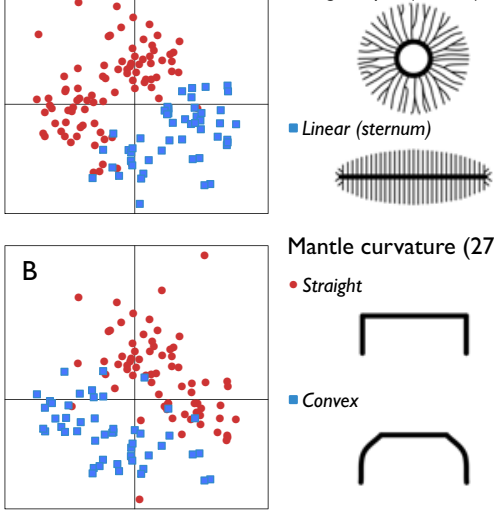

Mantle curvature (27)

- Straight

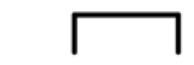

- Convex
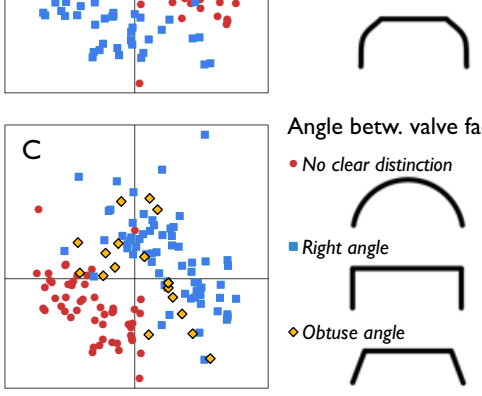

Angle betw. valve face and mantle (19)

- No clear distinction
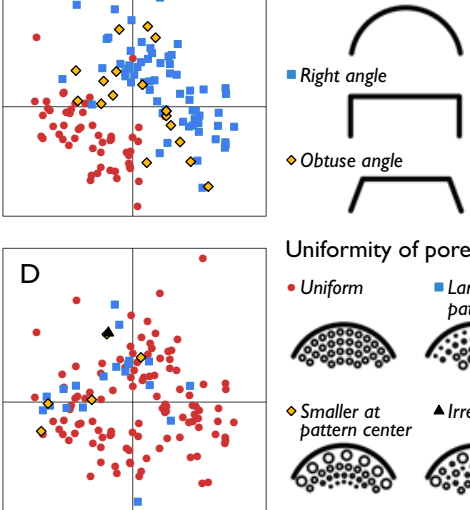

Uniformity of pore size (54)

- Uniform - Larger at

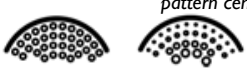

- Smaller at $\Delta$ Irregular
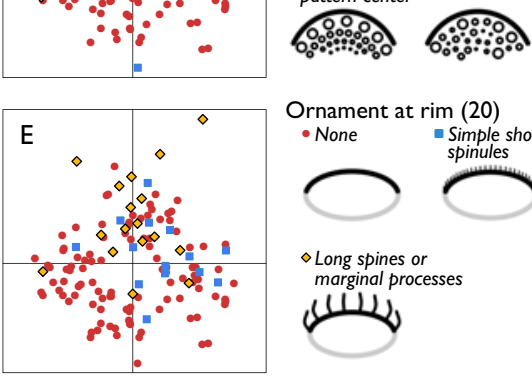

Ornament at rim (20)

- None Simple short

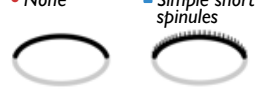

$\diamond$ Long spines or

marginal processe

(1)

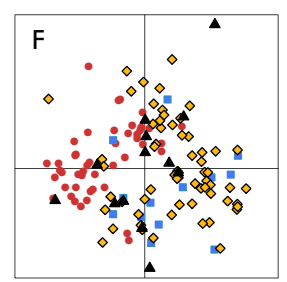
Packing of pores (49)
- Hexagonal $\quad$ Square
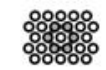

$\diamond$ In rows
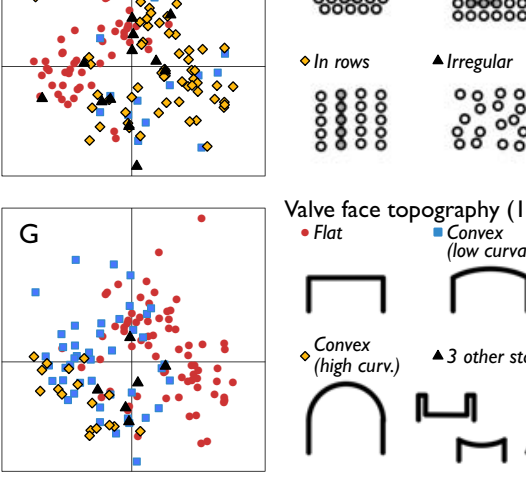

Valve face topography $(10)$

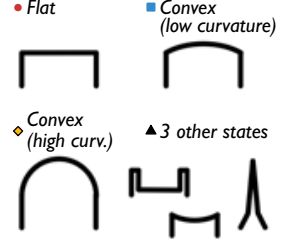




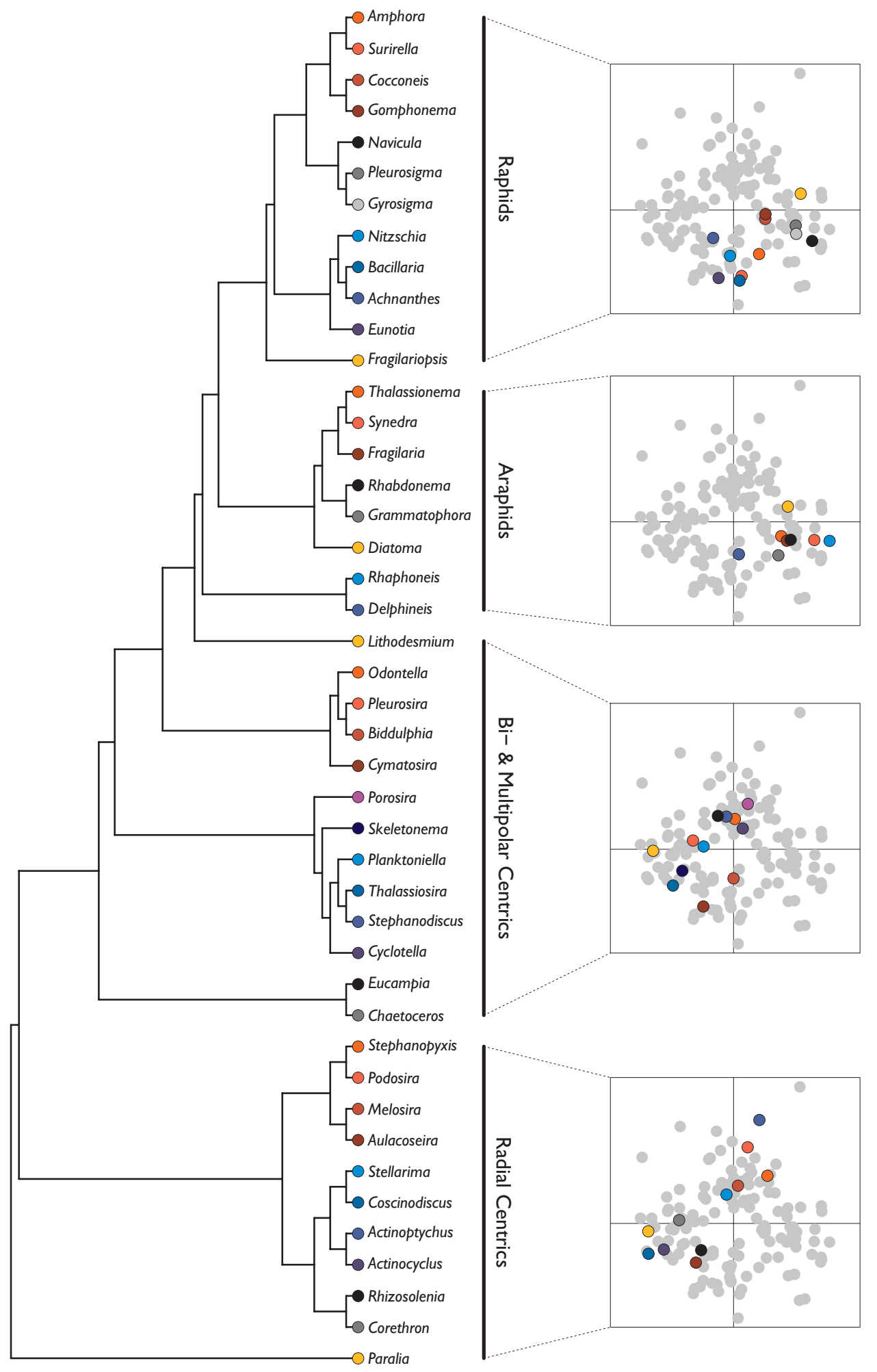




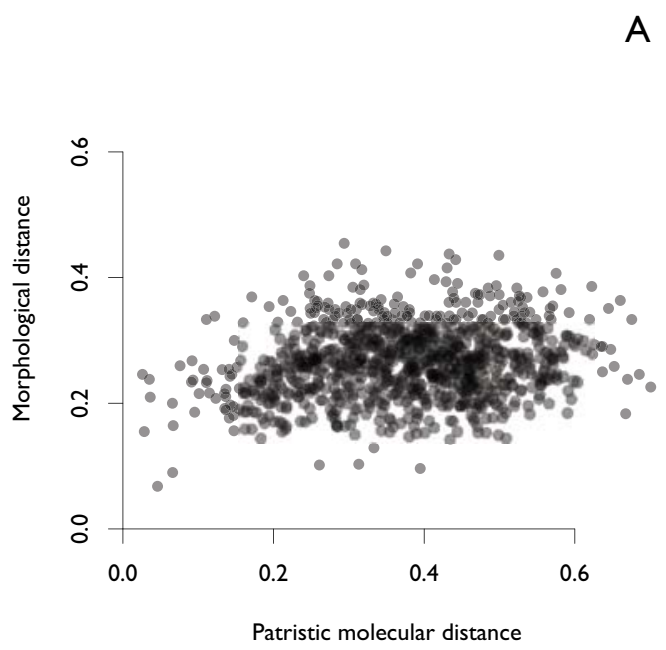

B

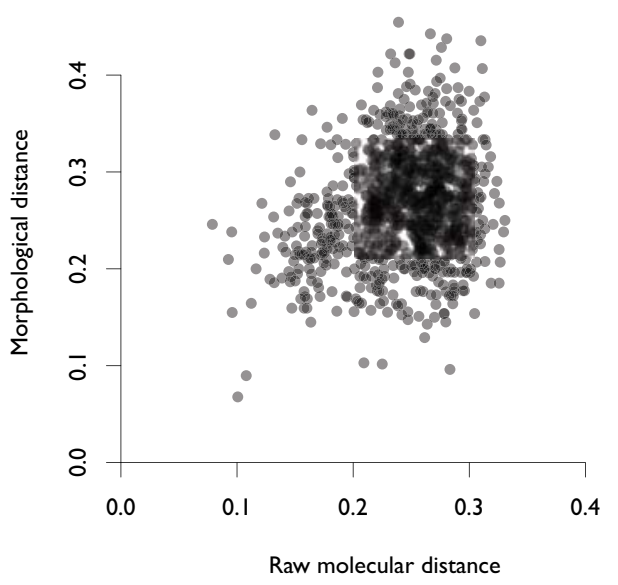




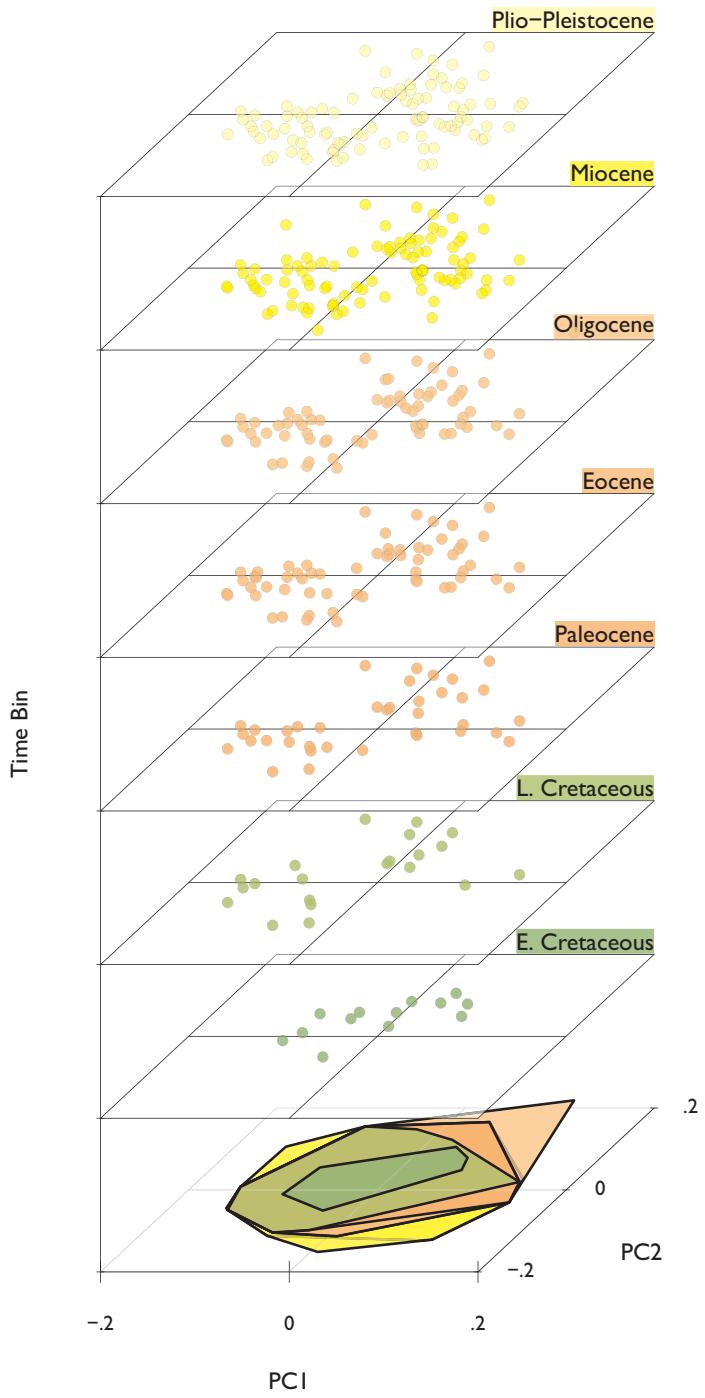



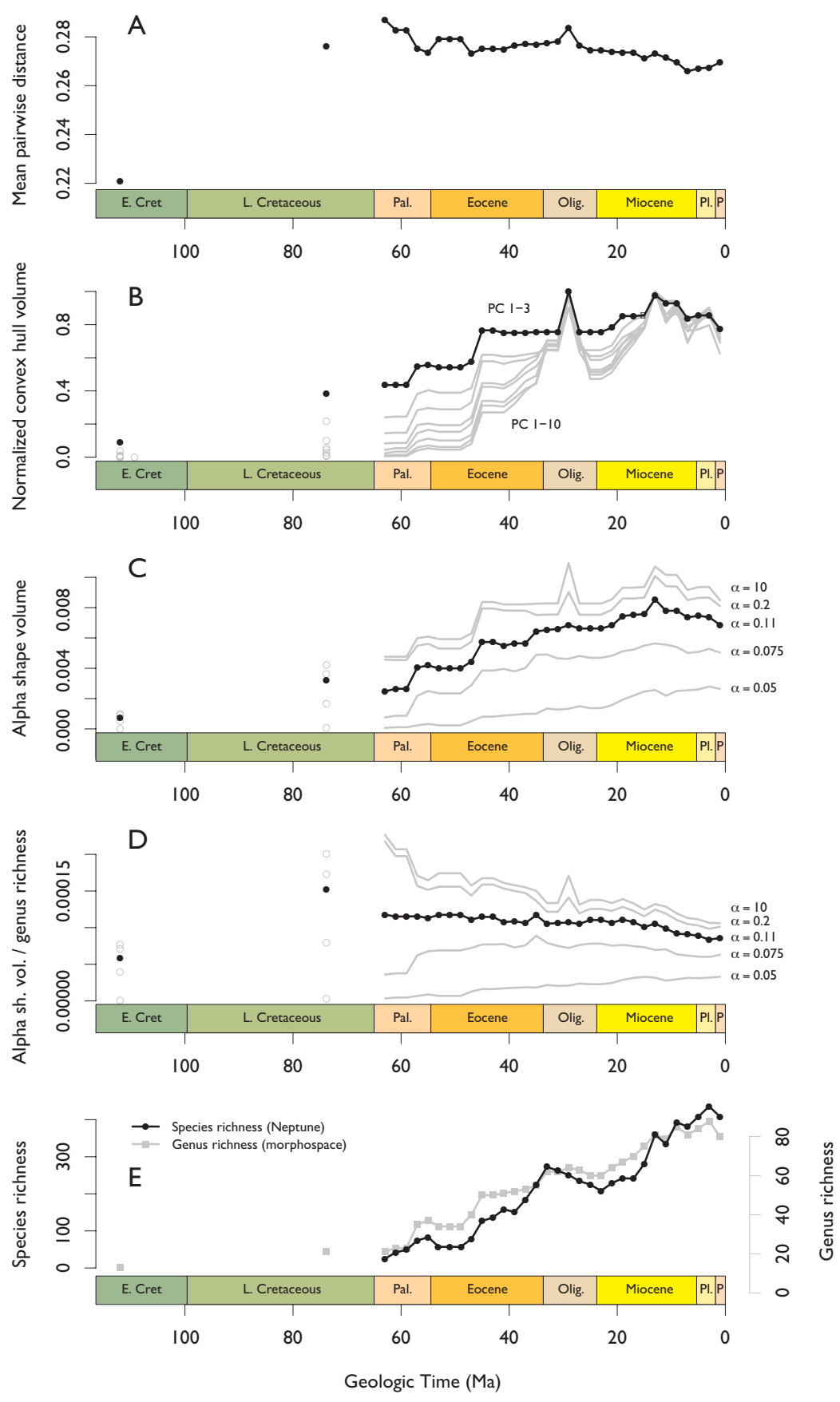

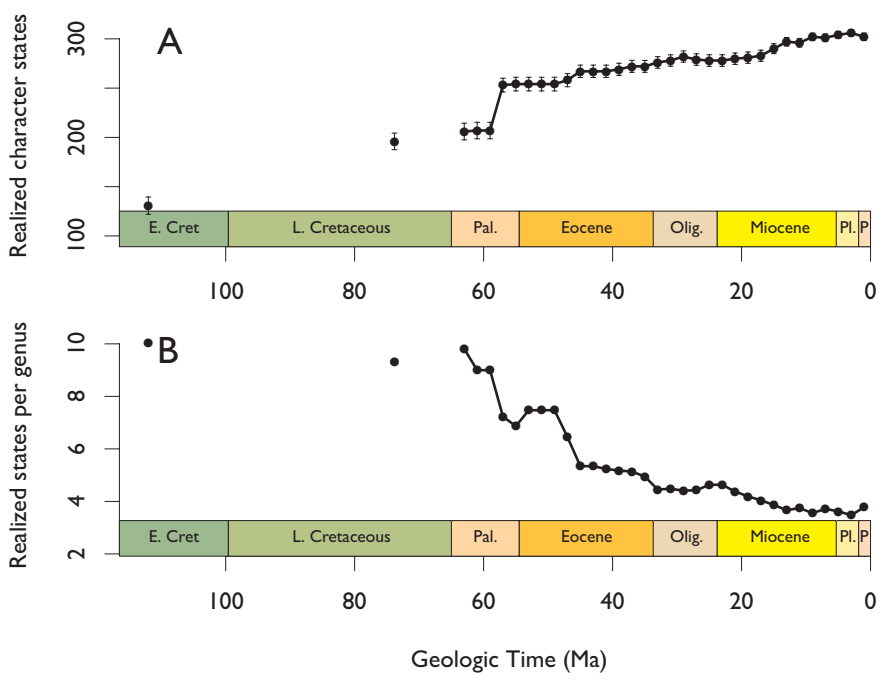


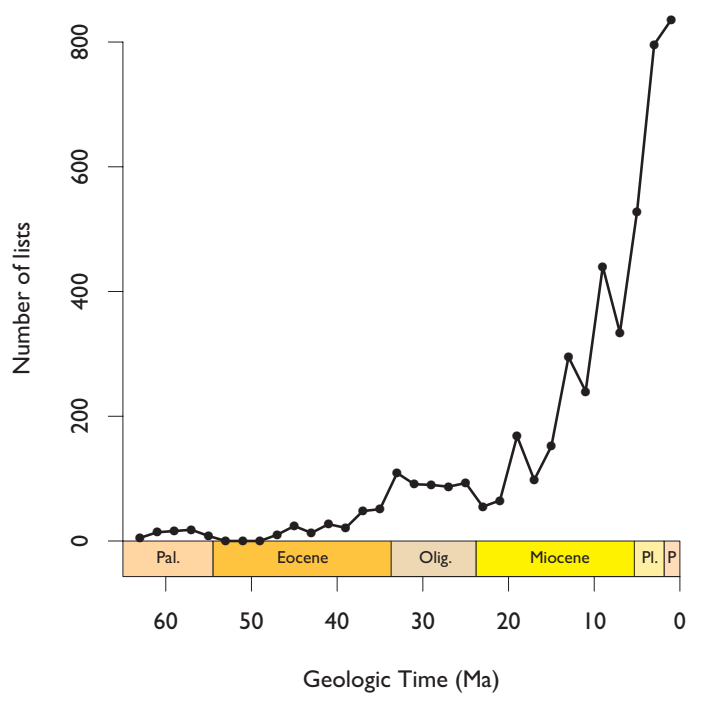


2 Table 1: The characters with the five highest Cramér coefficients and the five lowest associated

$3 p$-values on the first two PCO axes.

\begin{tabular}{|c|c|c|c|}
\hline Cramér coeff. & Axis & Char. & Character description \\
\hline$\overline{0.84}$ & PC 2 & 17 & Central elevation shape \\
\hline 0.63 & PC 2 & 14 & $\begin{array}{l}\text { Shape of apical elevation } \\
\text { summit }\end{array}$ \\
\hline $0.59 / 0.53$ & $\begin{array}{l}\mathrm{PC} \\
2 / \mathrm{PC} 1\end{array}$ & 27 & Mantle shape in cross section \\
\hline 0.58 & PC 1 & 100 & $\begin{array}{l}\text { Relative thickness of raphe } \\
\text { sides }\end{array}$ \\
\hline $0.57 / 0.50$ & $\begin{array}{l}\mathrm{PC} \\
1 / \mathrm{PC} 2\end{array}$ & 48 & $\begin{array}{l}\text { Shape of structural pattern } \\
\text { center }\end{array}$ \\
\hline 0.49 & PC 1 & 19 & $\begin{array}{l}\text { Angle between valve face and } \\
\text { mantle }\end{array}$ \\
\hline 0.45 & PC 2 & 92 & Raphe extent \\
\hline 0.44 & PC 1 & 84 & $\begin{array}{l}\text { Location of } \\
\text { process(es) }\end{array}$ \\
\hline
\end{tabular}

\begin{tabular}{|c|c|c|c|}
\hline$\underline{p \text {-value }}$ & Axis & Char & \#|Character description \\
\hline 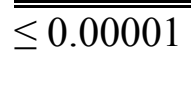 & $\begin{array}{l}\mathrm{PC} \\
1 / \mathrm{PC} 2\end{array}$ & 19 & $\begin{array}{l}\text { Angle between valve face and } \\
\text { mantle }\end{array}$ \\
\hline$<0.00001$ & PC 1 & 10 & $\begin{array}{l}\text { General topography of valve } \\
\text { face }\end{array}$ \\
\hline$<0.00001$ & PC 1 & 49 & Packing/coordination of pores \\
\hline$<0.00001$ & $\begin{array}{l}\mathrm{PC} \\
1 / \mathrm{PC} 2\end{array}$ & 48 & $\begin{array}{l}\text { Shape of structural pattern } \\
\text { center }\end{array}$ \\
\hline$<0.00001$ & PC 1 & 24 & Depth of mantle \\
\hline$<0.0$ & PC 2 & 27 & Mantle shape in cross section \\
\hline$<0.00001$ & PC 2 & 41 & Distinct central area \\
\hline 0.00003 & PC 2 & 22 & Marginal ridge at rim \\
\hline
\end{tabular}

